\title{
Evidence of reduced academic performance among school children with helminth infection independent of nutritional status
}

Emmanuel Timmy Donkoh ( $\square$ timmy.donkoh@uenr.edu.gh )

University of Energy and Natural Resources

Dorice Berkoh

Ivy Wina Ofori Boadu

Abdul Sakibu Raji

Samuel Asamoah

Samuel Fosu-Gyasi

Kenneth Bentum Otabil

John Ekow Otoo

Michael Tawiah Yeboah

Austin Gideon Adobasom-Anane

Simon Kofi Adams

Oksana Debrah

\section{Research Article}

Keywords: Academic performance, COVID-19, Malnutrition, School deworming, Soil transmitted helminths, Sub-Saharan Africa

Posted Date: January 24th, 2022

DOI: https://doi.org/10.21203/rs.3.rs-1153467/v1

License: (1) This work is licensed under a Creative Commons Attribution 4.0 International License.

Read Full License

Version of Record: A version of this preprint was published at International Health on May 24th, 2022. See the published version at https://doi.org/10.1093/inthealth/ihac044. 


\section{Abstract \\ Background}

Soil transmitted helminths (STH) pose a formidable health risk to school-age children in resource-limited settings. Unfortunately, mass deworming campaigns have been derailed since the onset of the COVID-19 pandemic. The present study assessed the cross-sectional associations between STH, nutritional status and academic performance of school children in the Banda District of Ghana.

\section{Methods}

School children (5-16 years) $(n=275)$ were recruited through both school and household visits by community health workers using a multi-stage cluster sampling technique. Weight and height measurements were taken for anthropometry, as well as stool microscopy.

\section{Results}

Prevalence of geo-helminthiasis was $40.4 \%$ (95\% Cl: $34.6 \%$ - 46.2\%). STH targeted for elimination by the world health organizations and national programmes were detected among school children. Children with intestinal parasite infection $(53.7 \pm 11.5)$ had lower mean academic scores compared to uninfected children (59.6 \pm 16.9$)(p=0.034)$. In multiple regression, intestinal parasite infection status and $z$-scores for weight-for-age showed a collective significant effect on academic score $(F(1,117)=8.169, p<0.001$, $\left.\mathrm{R}^{2}=.125\right)$.

\section{Conclusion}

School children with STH had poorer academic performance compared to uninfected children, in spite of their nutritional status. In addition to school-feeding programmes, school-based mass drug administration campaigns may be critical for improving learning outcomes in young school children.

\section{Introduction}

School-age children in developing countries are at risk of compromised health as a consequence of helminth infections $(1,2)$. Although helminth infections do not produce high mortality statistics, recent estimates suggest that morbidity due to helminth infections accounts for an estimated $20 \%$ of the disability-adjusted life years lost due to infectious diseases in children less than 14 years old (3). Among the well-described morbidities associated with helminth infection in children are under-nutrition, anemia, and failure to achieve genetic potential for growth (3). Much like other diseases of poverty, the burden of STH is disproportionately high in developing countries and affect children living in extreme poverty, particularly those living in rural communities or urban communities without adequate access to good 
water, sanitation, and hygiene (WASH) (2). In sub-Saharan Africa, estimates of the prevalence of hookworm (Ancylostoma duodenale and Necator americanus) range from 30-50\% (4). Environmental factors present in tropical climates are known to be conducive to the life-cycle of intestinal helminths that have been marked for eradication. Furthermore, soil transmitted helminths are thought to deepen inequality in society as well by widening of the wealth gap by adversely affecting future economic potential of children from poor socio-economic background (5).

Current World Health Organization (WHO) guidelines for the management of STH infections focus on morbidity control through the use of mass drug administration (MDA) of anthelmintic drugs targeting preschool- and school-aged children as well as other at-risk groups (6). In 2019, the School Health Education Programme (SHEP) Unit of the Ghana Education Service, and the neglected tropical disease (NTD) programme of Ghana Health Service with support of donor partners undertook school-based deworming campaigns in order to control the burden of STH. Under this initiative, school children from age 5 to 16 years were targeted for the administration of Albendazole (400 mg po) and Praziquantel (20 $\mathrm{mg} / \mathrm{kg}$ bid). The mass drug administration was held in 32,371 basic schools in 178 Districts across the country and covered approximately 6 million school children. Stakeholders were expected to build on the experiences of previous MDA campaigns conducted in November 2014, November 2015, and November 2019 to maximize the gains to be made in subsequent years.

Then came the pandemic. The COVID-19 pandemic had broad-range disruptive effects on in-country programmes targeted at several neglected tropical diseases (NTDs) including school deworming campaigns. In the Bono Region, all deworming campaigns halted in the wake of the pandemic as a result of the strain placed on the health service by the pandemic. Indeed, the Ghana Health Service had to readjust programme goals in order to mobilize adequate resources to manage the public health threat imposed by the pandemic. In addition, the Government ordered the closure of all basic schools for an entire academic year, effectively bringing an end to all school health programs. In the midst of all the chaos, drugs intended for distribution in rural communities where the greatest burden of soil transmitted helminths expired as a result of these extended lockdowns. Meanwhile, children continued to be exposed to community factors that placed them at heightened risk of infection with soil transmitted helminths with no access to drugs (7).

Several studies have highlighted a gap in knowledge and policy setting regarding the value of school deworming campaigns and children's academic performance or cognitive function (8-10). However, data on helminth infection in Ghana has largely focused on prevalence estimates for health disability and not on children's academic performance. The aim of the present study is to investigate the effect of soil transmitted helminth infections on growth (nutritional status) and cognitive function in school children in the Bono Region of Ghana in light of demographic, socio-economic, and epidemiologic contextual factors such as COVID-19 induced suspension of mass school-based deworming campaigns.

\section{Methodology}




\section{Study design and setting}

A cross sectional survey design was employed to determine the prevalence of intestinal helminths, anemia and academic performance among school children in the Banda district of the Bono Region of Ghana (Figure 1). The Banda District is made up of a number of riparian communities covering a total land area of 2,298.3 square kilometres in the middle belt of Ghana. It is home to a population of approximately 25,000 people. Majority of the inhabitants (71.2\%) find employment as skilled agricultural, forestry and fishery workers. The district is entirely rural with a youthful population. The District has a household population of 20,171 with a total number of 3,685 households. The average household size in the District is about 6 persons per household. Children constitute the largest proportion of the household members (41.7\%). The three main sources of lighting in dwelling units in the District are electricity (46.3\%), flashlight/torch (40.4\%) and kerosene lamp (11.8\%). The main source of fuel for cooking for most households in the District is wood (75.5\%). The four main sources of water in the District are borehole, river stream, public tap and pipe borne water (96.4\%). Almost six percent of the households drink water from river or stream, while 0.4 percent drinks water from dugout/pond/lake/dam/canal. The most commonly used toilet facility in the District is open defaecation in the bush/field accounting for 43.9 percent followed by public toilet (34.2\%). Only 3.4 percent of the households in the District have WC toilet facility. With reference to school attendance, of the population aged 3 years and above, 62.5 percent are currently attending school and 37.5 percent have attended in the past.

\section{Sampling technique and data collection}

A total of 275 school-aged children (5-16 years) were recruited through school visits by community health workers using a multi-stage cluster sampling technique. The study was conducted in seven (7) selected basic schools three (3) of which were under private ownership. The register of schools in the district were obtained from the School Health Education Programme (SHEP) office. Schools were clustered according to location and stratified according to educational level (basic grade 1-9). Allocation of the students to schools and grade level were performed according to the number of students in each school and grade (Supplementary File 1: Allocation of schools). Study subjects were selected by systematic random sampling using the class roster as the sampling frame in each school. A validated and pretested questionnaire based on known risk factors was administered to each child-parent pair by trained field workers with translation to local dialect where necessary. Data about socio-demographic characteristics and risk for intestinal helminthic infections were retrieved through face-to-face interviews with parentchild units. Afterwards, blood samples were collected into $\mathrm{K}_{3}$ EDTA and gel tubes. Stool samples were collected into labeled, clean, and dry stool containers and preserved with $10 \%$ formalin before they were transported to the Banda District hospital laboratory. Weight and height measurements were taken in duplicate with minimal clothing, without shoes, and the mean values recorded. The anthropometric index of Z-score for weight-for-age was computed as an indicator of growth status for school children using Anthroplus software version 1.0.4 (WHO, Geneva). School children were classified as underweight if they had Z-score values less than 2 times the SD for weight-for-age. The academic performance of the 
students was measured as the cummulative end-of-term examination results averaged over 3 consecutive school terms.

\section{Laboratory procedures}

Preserved stool samples were processed using the formalin-ether concentration method (11). Briefly, a portion of stool weighing approximately $2 \mathrm{~g}$ was placed in a separate stool container and mixed with $10 \mathrm{ml}$ of $10 \%$ formalin, filtered through two layers of gauze into a $15 \mathrm{ml}$ centrifuge tube and centrifuged at 2000 rpm for 2 min. The sample was stirred thoroughly and incubated for 5 minutes before addition of $3 \mathrm{ml}$ diethyl ether and centrifugation at $2000 \mathrm{rpm}$ for 2 minutes. The supernatant was discarded and the sediment was used to prepare a smear on a microscopic slide for observation of parasite ova. Blood films (thin and thick) were prepared and examined according to WHO guidelines to check for the presence

of blood parasites (Plasmodium) (1). Haemoglobin concentration levels were measured on an automated analyser (SYSMEX KX-21N, Chuo-ku, Kobe, Japan) using whole blood collected in EDTA test tubes.

\section{Statistical analysis}

Statistical Package for Social Sciences (SPSS) for windows version 25.0 was used to analyse collected data. Associations between variables and were tested via bivariate analysis (chi-square test). Bivariate correlations, independent T-tests, and multiple regression analyses were performed to investigate associations between academic performance, helminth infection and nutritional status.

\section{Ethical consideration}

Ethical clearance was obtained from the Committee for Human Research and Ethics of the University of Energy and Natural Resources, School of Sciences, reference number CHRE/AP/08/021 and the Committee on Human Research Publication and Ethics, School of Medical Sciences, Kwame Nkrumah University of Science and Technology Kumasi, Ghana with reference number CHRPE/AP/140/21. Participants recruited for the study provided written informed consent (i.e. the participants gave assent and their parents gave consent).

All the individuals diagnosed to have intestinal protozoan infections were given metronidazole (Flagyl) orally as standard adult dose (800 mg) or standard paediatric dose (200-400mg) 8-hourly for five days. Furthermore, those found to have schistosome infection received a standard oral dose of praziquantel (40 mg/kg body weight). Children infected with intestinal helminths received albendazole (400 mg) in a single dose as recommended by the NTD programme and standard treatment guidelines of the Ghana Health Service.

\section{Results}

A total of 275 school children aged 5 to 16 years were recruited for the study. All of them provided a blood sample and stool sample. Demographic characteristics of the participants are shown in Table 1. The mean age of the children was 11.1 years (SD: \pm 2.4 years). Majority of the participants were females accounting for 156 (56.7\%) of the total study population. Approximately two-thirds (65.8\%) of study 
participants were descended from the Mole-Dagbani ethnicity and the rest were mostly Akans (31.3\%) with a minority group of Ga-Adangbe descent. The major religious persuasion was Islam (56\%). Majority of the participants were attending public schools under the Ministry-funded meal supplementation programme (73.1\%). The mean blood haemoglobin concentration was recorded as $10.9 \mathrm{~g} / \mathrm{dL}$ (SD: \pm 1.7 $\mathrm{g} / \mathrm{dL})$.

Table 1

Demographic characteristics of school children

\begin{tabular}{|lll|}
\hline Parameter & Frequency & Percentage (\%) \\
\hline Total & 275 & 100 \\
\hline Gender & & \\
\hline Male & 119 & 43.3 \\
\hline Female & 156 & 56.7 \\
\hline Ethnic Group & & \\
\hline Akan & 86 & 31.3 \\
\hline Ga-Adangbe & 8 & 2.9 \\
\hline Mole-Dagbane & 181 & 65.8 \\
\hline Religion & & \\
\hline Christianity & 121 & 44.0 \\
\hline Islamic & 154 & 56.0 \\
\hline Class of Participant & & \\
\hline KG and Lower Primary & 105 & 38.2 \\
\hline Upper Primary and JHS & 170 & 61.8 \\
\hline Coverage of School Feeding Programme & & \\
\hline Covered & 201 & 73.1 \\
\hline Not covered & 74 & 26.9 \\
\hline Parameters & Mean & Min-Max \\
\hline Age of Respondent (N=275) & $11.1 \pm 2.4$ & $5-16$ \\
\hline Haemoglobin concentration (g/dL) (N=275) & $10.9 \pm 1.7$ & $20.1-99.2$ \\
\hline Academic score (\%) (N=117) & & \\
\hline Data is presented as frequency and percentage. & \\
\hline & & \\
\hline
\end{tabular}


Table 2 shows the infection status of the school children. Out of the 275 stool samples examined, 154 $(56.0 \%)$ were positive for one or more intestinal or blood parasite. Prevalence of intestinal parasite infections (helminth and intestinal protozoa) was 49.5\% (95\% Cl: 43.5\% - 55.4\%). Intestinal helminths targeted for elimination were detected in $40.4 \%$ (95\% Cl: $34.6 \%-46.2 \%)$ of all cases. Commonly detected intestinal parasites were Taenia sp. (68/275, 24.7\%), Schistosoma spp. (20/275, 7.3\%), Ascaris spp. (17/275, 6.2\%), Ancyclostoma spp (11/275, 4.0\%) and Trichuris trichiura (7/275, 2.5\%). Prevalence of plasmodium detection was $5.5 \%(n=15)$. 
Table 2

Infection status of school children

\begin{tabular}{|c|c|c|}
\hline Parameter & Frequency (n) & Percentage (\%) \\
\hline Total & 275 & 100 \\
\hline \multicolumn{3}{|l|}{ Infection Status ${ }^{a}$} \\
\hline Uninfected & 121 & 44.0 \\
\hline Infected & 154 & 56.0 \\
\hline \multicolumn{3}{|l|}{ Intestinal parasites ${ }^{b}$} \\
\hline None & 139 & 50.5 \\
\hline Intestinal parasite infection & 136 & 49.5 \\
\hline \multicolumn{3}{|l|}{ Helminth infection } \\
\hline None & 164 & 59.6 \\
\hline Yes & 111 & 40.4 \\
\hline \multicolumn{3}{|l|}{ Prevalence of helminth infection } \\
\hline Strongyloides spp.(threadworm) & 6 & 2.2 \\
\hline Ancyclostoma spp & 11 & 4.0 \\
\hline Ascaris spp. (roundworm) & 17 & 6.2 \\
\hline Taenia spp. (tapeworm) & 68 & 24.7 \\
\hline Enterobius spp.(pinworm) & 4 & 1.5 \\
\hline Trichuris trichiura & 7 & 2.5 \\
\hline Trichostrongyloide spp. & 1 & 0.4 \\
\hline Schistosoma spp. & 20 & 7.3 \\
\hline \multicolumn{3}{|l|}{ Multiple helminth infection $(n=111)$} \\
\hline No & 82 & 73.9 \\
\hline Yes & 29 & 26.1 \\
\hline Entamoeba spp. & 54 & 19.6 \\
\hline
\end{tabular}

Data is presented as frequency and percentage. Infection Status ${ }^{a}$ : infection with either intestinal parasite and/or blood protozoa. Intestinal parasite Infection Status ${ }^{b}$ : infection with either intestinal helminth and/or intestinal protozoa. Mixed Infectionc: A combination of blood-borne protozoa and intestinal parasites. 
Parameter

Blood-borne protozoa

None

Plasmodium spp.

Mixed Infection ${ }^{c}$

No mix infection

Mixed infection
260

94.5

15

5.5

267

97.1

Frequency (n)

Percentage (\%)

$\begin{array}{ll}8-9 & 2.9\end{array}$

Data is presented as frequency and percentage. Infection Status ${ }^{a}$ : infection with either intestinal parasite and/or blood protozoa. Intestinal parasite Infection Status ${ }^{b}$ : infection with either intestinal helminth and/or intestinal protozoa. Mixed Infection ${ }^{\mathrm{c}}$ : A combination of blood-borne protozoa and intestinal parasites.

Out of the 275 blood samples, 142 had low Hb levels representing an anaemia prevalence of $51.64 \%$. The mean $\mathrm{Hb}$ level of school children was $10.9 \mathrm{~g} / \mathrm{dL}(\mathrm{SD}: \pm 1.7 \mathrm{~g} / \mathrm{dL}$ ) ranging from $6.4 \mathrm{~g} / \mathrm{dL}$ to $17.6 \mathrm{~g} / \mathrm{dL}$ (Table 1). Table 3 shows results from a chi-square test of association between Hemoglobin $(\mathrm{Hb})$ level and intestinal parasite infection status ( $x 2$-Value $=9.163, d f=1, p-$ Value $=0.002)$. Children with intestinal parasite infections were more likely to be classified as having a low Hb result $(p=0.002)$. Out of the 136 helminth infected children, 83 (58.45\%) had low $\mathrm{Hb}$.

Table 3

The association of haemoglobin and helminth status

$\begin{array}{llll}\text { Parameter } & \text { Hb Status } & & \\ & \text { Normal } & \text { Anaemia }^{d} & \text { Total } \\ \text { Total } & 133 & 142 & 275 \\ & (48.36 \%) & (51.64 \%) & (100.00 \%)\end{array}$

Intestinal Parasites

No infection

$80(60.15 \%)$

$59(41.55 \%)$

139 (50.55\%)

9.163

$1 \quad 0.002$

Intestinal parasite

$53(39.85 \%)$

$83(58.45 \%)$

$136(49.45 \%)$

infection

\section{Helminth infection status}

No infection

95(57.90\%)

$69(42.10 \%)$

$164(59.60 \%)$

14.879

1

0.000

Helminth infection

38(34.20\%)

$73(65.80 \%)$

$111(40.40 \%)$

Anaemiad: defined as Hemoglobin $(\mathrm{Hb})$ level $<11.5 \mathrm{~g} / \mathrm{dL}(30)$. Intestinal parasite infection: infection with either intestinal helminth and/or intestinal protozoa 
Academic performance scores averaged over two school terms were compared across categories of

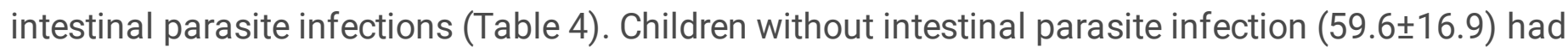
higher mean academic scores compared to children with intestinal parasite infection (53.7 \pm 11.5$)$ $(t=2.148, d f=91.277, p-v a l u e=0.034)$. Infected children $(53.6 \pm 11.5)$ performed poorly compared to uninfected children (59.9 \pm 16.9$)$. There was no difference in academic performance between school children who were underweight $(61.5 \pm 18.5)$ and normal weight $(55.6 \pm 13.6)(t=-1.579, d f=115, p-$ value $=0.117$ ). 
Table 4

Comparison of academic performance across health status of participants

\section{Parameter}

Intestinal parasites ${ }^{d}$

No infection $(\mathrm{N}=54)$

Intestinal parasite infection $(\mathrm{N}=63)$

Helminth infection

No infection $(\mathrm{N}=66)$

Helminth infection $(\mathrm{N}=51)$

Blood parasites ${ }^{\mathrm{e}}$

No infection $(\mathrm{N}=114)$

Plasmodium spp. $(\mathrm{N}=3)$

$56.5 \pm 14.6$

0.483

115

0.63

$52.4 \pm 8.8$

Mixed Infection ${ }^{f}$

No infection $(\mathrm{N}=115)$

Mixed infection ( $\mathrm{N}=2)$

$56.4 \pm 14.6$

$-0.003$

115

0.998

$56.5 \pm 7.6$

Infection Status ${ }^{a}$

Not infected $(\mathrm{N}=53)$

$59.9 \pm 16.9$

2.296

88.618

0.024

Infected $(\mathrm{N}=64)$

$53.6 \pm 11.5$

\section{Nutritional status}

Normal weight-for-age

$55.6 \pm 13.6$

$-1.579$

115

0.117

Low weight-for-age

$61.5 \pm 18.5$

Data is presented as mean \pm standard deviation. Df: degree of freedom, $p$-value $<0.05$ is considered significant. Intestinal parasites ${ }^{\mathrm{d}}$ : infection with intestinal parasites only. Blood parasites ${ }^{\mathrm{e}}$ : infection with Plasmodium spp. Mixed Infection ${ }^{\text {f: }}$ A combination of blood-borne protozoa and intestinal parasites. Infection Status ${ }^{g}$ : infection with either intestinal parasite and/or blood protozoa.

Figure 1 shows the prevalence of underweight (low weight-for-age) among the school children. The general prevalence of underweight among the school children was $13.1 \%(36 / 275)$. Among the school children, $19.3 \%$ (23/119) males were underweight and 8.3\% (13/156) females were underweight.

Academic performance scores averaged over two school terms were compared across categories of socio-demographic variables (Table 5). Children from low-income households $(52.5 \pm 12.9)$ performed 


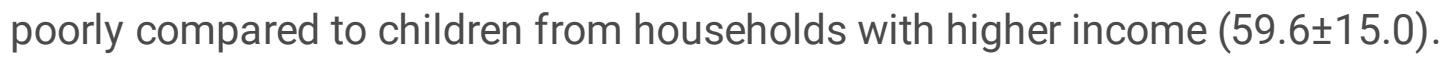

Table 5

Comparison of academic performance according to demographic characteristics of school children.

\begin{tabular}{|c|c|c|c|c|}
\hline Parameter & Academic Performance & T- Statistic & df & P- Value \\
\hline \multicolumn{5}{|l|}{ Sex } \\
\hline Male $(\mathrm{N}=54)$ & $56.0 \pm 13.8$ & -0.315 & 115 & 0.753 \\
\hline Female (63) & $56.8 \pm 15.2$ & & & \\
\hline \multicolumn{5}{|l|}{ Household size } \\
\hline 7 and below $(\mathrm{N}=54)$ & $57.3 \pm 15.3$ & 0.607 & 115 & 0.545 \\
\hline Above $7(\mathrm{~N}=63)$ & $55.7 \pm 13.9$ & & & \\
\hline \multicolumn{5}{|l|}{ Household income } \\
\hline GHC 150 and below $(\mathrm{N}=52)$ & $52.5 \pm 12.9$ & -2.675 & 115 & 0.009 \\
\hline Above GHC 150 (N=65) & $59.6 \pm 15.0$ & & & \\
\hline \multicolumn{5}{|l|}{ Household weekly expenditure } \\
\hline GHC 50 and below ( $N=76)$ & $55.0 \pm 13.8$ & -1.444 & 115 & 0.151 \\
\hline Above GHC $50(\mathrm{~N}=41)$ & $59.1 \pm 15.5$ & & & \\
\hline \multicolumn{5}{|l|}{ Class of Participants } \\
\hline KG and Lower Primary $(\mathrm{N}=39)$ & $55.1 \pm 15.1$ & -0.718 & 115 & 0.474 \\
\hline Upper Primary and JHS ( $\mathrm{N}=78)$ & $57.1 \pm 14.2$ & & & \\
\hline $\begin{array}{l}\text { Data is presented as mean } \pm \text { sta } \\
\text { significant. }\end{array}$ & deviation. Df: degree of $f$ & m, p-value & 05 wa & onsidered \\
\hline
\end{tabular}

In the multiple regression model, intestinal parasite infection status and z-scores for weight-for-age explained $12.5 \%$ of the variability in academic scores $\left(F(1,117)=8.169, p<0.001, R^{2}=.125\right)$. As shown in Table 6, both intestinal parasite infection status $(t=-2.026, p=0.045)$ and $z$-scores for weight-for-age ( $t=$ -3.321, $p=0.001$ ) were significant predictors of the academic score. However, the relationship between intestinal parasite infection status $(t=-1.648, p=0.102)$ and academic scores was undermined when household income was added to the model $\left(F(2,117)=7.408, p<0.001, R^{2}=.164\right)$ as shown in Table 7 . 
Table 6

Determinants of school children's academic performance over past year (model 1)

\begin{tabular}{|c|c|c|c|c|c|c|}
\hline \multicolumn{2}{|c|}{ Model } & \multicolumn{2}{|c|}{$\begin{array}{l}\text { Unstandardized } \\
\text { Coefficients }\end{array}$} & \multirow{2}{*}{$\begin{array}{l}\text { Standardized } \\
\text { Coefficients } \\
\text { Beta }\end{array}$} & \multirow[t]{2}{*}{$\mathbf{T}$} & \multirow[t]{2}{*}{$\begin{array}{l}\mathrm{P} \text { - } \\
\text { value. }\end{array}$} \\
\hline & & B & Std. Error & & & \\
\hline \multirow[t]{3}{*}{1} & (Constant) & 59.912 & 1.862 & & 32.177 & .000 \\
\hline & $\begin{array}{l}\text { Intestinal parasite } \\
\text { infection }\end{array}$ & -5.152 & 2.542 & -.178 & -2.026 & .045 \\
\hline & Zscore: weight for age & -3.577 & 1.077 & -.292 & -3.321 & .001 \\
\hline \multicolumn{7}{|c|}{ a. Dependent Variable: Academic Performance } \\
\hline \multicolumn{7}{|c|}{ b. $R^{2}=.125, F=8.169, p<0.001$} \\
\hline
\end{tabular}

Table 7

Determinants of school children's academic performance over past year (model 2).

\begin{tabular}{|c|c|c|c|c|c|c|}
\hline \multicolumn{2}{|c|}{ Model } & \multicolumn{2}{|c|}{$\begin{array}{l}\text { Unstandardized } \\
\text { Coefficients }\end{array}$} & \multirow{2}{*}{$\begin{array}{l}\text { Standardized } \\
\text { Coefficients } \\
\text { Beta }\end{array}$} & \multirow[t]{2}{*}{$\mathrm{T}$} & \multirow[t]{2}{*}{$\begin{array}{l}\mathrm{P} \text { - } \\
\text { value. }\end{array}$} \\
\hline & & B & Std. Error & & & \\
\hline \multirow[t]{4}{*}{1} & (Constant) & 50.309 & 4.567 & & 11.017 & .000 \\
\hline & $\begin{array}{l}\text { Intestinal parasite } \\
\text { infection }\end{array}$ & -4.172 & 2.532 & -.144 & -1.648 & .102 \\
\hline & Zscore: weight for age & -3.467 & 1.059 & -.283 & -3.275 & .001 \\
\hline & Household income & 5.820 & 2.536 & .201 & 2.295 & .024 \\
\hline \multicolumn{7}{|c|}{ a. Dependent Variable: Academic Performance } \\
\hline \multicolumn{7}{|c|}{ b. $R^{2}=.164, F=7.408, p<0.001$} \\
\hline
\end{tabular}

\section{Discussion}

In the wake of the first cases of SARS CoV 2 infections in Ghana, the Government took several precautionary measures to avoid community-spread and contain the virus. As part of these measures, school activities were suspended and school children had to stay at home for over a year. By compelling national authorities to lock down schools, the COVID-19 pandemic completely disrupted mass drug administration campaigns previously held in schools. Furthermore, children staying at home faced a greater risk of reinfection from community-acquired helminths (7). Once restrictions had been eased and schools allowed to reopen, the present study investigated the burden of helminth infections in an endemic community and to investigate the cross-sectional relationship with nutritional status and school performance. 
A high burden (40.4: 95\% Cl: $34.6 \%-46.2 \%)$ of STH was detected among school children. Several classes of intestinal parasites were present in stool samples collected from school-age children: these included Taenia spp., Schistosoma spp., Strongyloides spp., Ascaris spp., and Entamoeba spp. Estimates of the prevalence of STH among school children in Ghana have ranged from $6-45 \%(4,12,13)$ under varying contexts. Abera et al., (2014) recorded a prevalence of 41.46 percent in an area in Northern Ethiopia, while Davies and colleagues also recorded a frequency of 40.5 percent and 40.7 percent among preschool and school-aged children, respectively $(14,15)$. The prevalence of hookworms (Ancylostoma duodenale and Necator americanus) was however much lower in the present study than what had been previously known (30-50\%) prior to the onset of MDA in schools $(16,17)$.

In Ghana, sporadic community-based administration of anti-helminth agents to school children in targeted communities as part of eradication efforts have been reported to lower the burden of helminths reported in communities with such a history (17). The low prevalence of hookworm may reflect the impact of previous deworming campaigns in the Region (4). However, this may be difficult to prove in the absence of pre-MDA campaign data on the Banda District where the present study was conducted.

Nevertheless, the burden of intestinal parasites and helminths is higher than other estimates in schoolage children from the region $(4,18-20)$. In addition, they remain far above elimination targets set by the WHO. The variation in prevalence might be due to research scheduling, participant sampling, seasonal changes in survey conduct, environmental circumstances, or other geographical characteristics in these study locations.

The higher-than-expected burden of soil transmitted helminths discovered among school-age children several months after a mass deworming exercise in the Region might be indicative of persistent reinfection patterns (7) and reflect the impact of the pandemic in diminishing control efforts implemented through the school system. In the absence of control measures aimed at reducing exposure, treatment of STH infections will naturally be followed by avoidable re-infection, necessitating repeated treatments ( 21 , 22). As such, to sustain the benefits of treatment well beyond campaign periods and to preempt the adverse effects of future public health shocks such as the COVID-19 pandemic on gains made through MDA programmes, efforts to reduce environmental exposure to infection through improved sanitation and hygiene behaviors must be prioritized (23-25). Transmission of protozoa that live in a human's intestine to another human typically occurs through the fecal-oral route (for example, contaminated food or water or person-to-person contact). Thus, the high prevalence of Entamoeba spp. in the community would suggest that insanitary conditions exist that need to be improved.

Inhabitants living in close proximity to water bodies have been reported to maintain significantly elevated relative risks for helminth infections and might also be a reason for the burden of helminths observed in the Banda District of the Bono Region where contact with stagnant water bodies is an important part of daily life especially for children who are continuously exposed to contaminated soil and water and often lack the awareness of good personal hygiene. Gyasi et al., (2019) investigated the incidence and the prevalence of Schistosoma haematobium infection in riparian communities of the Bui dam. The study 
revealed that, $S$. haematobium was more prevalent among inhabitants living closer to the Bui dam with children less than 14 years of age being the worst affected (26). As a result, control efforts must factor the contextual requirements within such geographic locations in order to achieve and sustain programme targets.

In general, a high burden of intestinal parasites and helminths in particular have been strongly linked with poor nutritional status and anaemia (3). The high prevalence of anaemia among school children in the study area and the significant cross-sectional association between intestinal parasite infection and suboptimal haemoglobin concentration confirm this assertion (Table 3). When unchecked, poor nutritional status and anaemia may undermine academic performance in school children. However, the present data did not reveal an association between poor nutritional status and academic performance. A number of reasons may be ascribed to this including the broad age range (5-16) and the sensitivity of markers of nutrition across the age spectrum $(1,27)$. More comprehensive nutritional assessment based on anthropometric, biochemical and clinical data is required to confirm this finding.

Rather, academic performance averaged from scores over two school terms was significantly associated with intestinal parasite status (Tables 5-7). A number of similar studies have reported concordant findings $(8,28)$. This adds to the growing body of data in support of an association between academic performance of school children and helminthiasis (Supplementary file 2: Determinants of school children's academic performance over past year). Several mechanisms have been put forward to explain this association, including an improvement in school attendance following mass deworming of school children during the academic year (13). Not all studies report a significant relationship between children's cognitive performance and their anthropometric and helminthiasis data (29). In addition to intestinal parasite status, low household income level was associated with poor academic performance. Children from low-income households performed poorly compared to children from households with higher income (Table 5-7). Academic performance is an important socioeconomic objective for every society. In the broadest sense, it provides an indication of the fortunes of the society in the near future. However, this finding suggests that significant investment may be needed to offset household poverty and guarantee quality educational outcomes. Recognizing this, the Government has introduced a policy to provide free school meals to school children. However, aside meal supplementation, mass deworming campaigns may be crucial for attaining expected educational targets.

\section{Conclusion}

Data collected immediately after the easing of COVID-19 restrictions among school children in the Banda District of Ghana show that the prevalence of soil transmitted helminths is $40.4 \%$ and higher than programme targets. Commonly detected intestinal parasites were Taenia spp., Schistosoma spp., Ascaris spp., Ancyclostoma spp. and Trichuris trichiura. Helminth infection, either independently or together with Entamoeba spp., household income and z-scores for weight-for-age may be important predictors of academic performance for school children. School children with intestinal parasite infection had poorer academic performance compared to uninfected children, in spite of their nutritional status. In addition to 
school-feeding programmes, consistent mass drug administration campaigns may be critical for improving learning outcomes in young school children.

\section{Declarations}

\section{Authors' contributions}

ETD, DB, SFG and MTY conceived the study; KBO, WIOB and JEO designed the study protocol and trained field and laboratory staff; JEO, BAA and SKA carried out the clinical assessment; OD, SA and ASR carried out the laboratory and data analysis and interpretation. ETD, AGAA and OD drafted the manuscript; BAA, SFG and WIOB critically revised the manuscript for intellectual content. All authors read and approved the final manuscript. ETD and DB are guarantors of the paper

\section{Acknowledgements}

The authors wish to acknowledge Mrs. Efua Arthur-Amissah, School Health Education Programme Coordinator for Banda District and Mr. Amproche Amprofi and the Earth Observation and Research Center (EORIC) at the University of Energy and Natural Resources for generating a map of the study area. Special thanks to members of the Screen \& Treat Research Group who contributed in diverse ways to this work: Dr. Kwame O. Boadu, Kumasi South Hospital; Dodzi Amelor, National Public Health Reference Laboratory; Prof. Christian Obirikorang, Department of Molecular Medicine, KNUST; Dr. Edward T. Dassah, School of Public Health, KNUST; Dorothy Asubonteng Appianing, Enoch Afful and Barimah Ansah, Department of Medical Laboratory Science, UENR. The authors are grateful to the Neglected Tropical Diseases (NTD) programme of the Ghana Health Service for providing medication for infected children.

\section{Funding}

None

\section{Competing interest}

None declared.

\section{Ethical approval}

Ethical clearance was obtained from the Committee for Human Research and Ethics of the University of Energy and Natural Resources, School of Sciences, reference number CHRE/AP/08/021 and the Committee on Human Research Publication and Ethics, School of Medical Sciences, Kwame Nkrumah 
University of Science and Technology Kumasi, Ghana with reference number CHRPE/AP/140/21. All protocols were in line with the Helsinki Declaration. Participants recruited for the study provided written informed consent (i.e. the participants gave assent and their parents gave consent).

\section{Data Availability}

The data underlying this article will be shared on reasonable request to the corresponding author.

\section{References}

1. Abdi M, Nibret $E$, Munshea $A$; Prevalence of intestinal helminthic infections and malnutrition among schoolchildren of the Zegie Peninsula, northwestern Ethiopia. J Journal of infection public health 2017;10(1):84-92.

2. Tchuenté LT; Control of soil-transmitted helminths in sub-Saharan Africa: diagnosis, drug efficacy concerns and challenges. J Acta tropica 2011;120:S4-S11.

3. Weatherhead JE, Hotez PJ, Mejia R; The global state of helminth control and elimination in children. $J$ Pediatric clinics 2017;64(4):867-877.

4. Adu-Gyasi D, Asante KP, Frempong MT, et al.; Epidemiology of soil transmitted Helminth infections in the middle-belt of Ghana, Africa. Parasite epidemiology control 2018;3(3):e00071.

5. Ahuja A, Baird S, Hicks JH, et al.; When should governments subsidize health? The case of mass deworming. The World Bank Economic Review 2015;29(suppl_1):S9-S24.

6. WHO; Guideline: preventive chemotherapy to control soil-transmitted helminth infections in at-risk population groups. Geneva World Health Organization, 2017.

7. Krause RJ, Koski KG, Pons E, et al.; Ascaris and hookworm transmission in preschool children from rural Panama: role of yard environment, soil eggs/larvae and hygiene and play behaviours. $J$ Parasitology 2015;142(12):1543-1554.

8. Pabalan N, Singian E, Tabangay L, et al.; Soil-transmitted helminth infection, loss of education and cognitive impairment in school-aged children: A systematic review and meta-analysis. PLOS neglected tropical diseases 2018;12(1):e0005523.

9. Mireku MO, Boivin MJ, Davidson LL, et al.; Impact of helminth infection during pregnancy on cognitive and motor functions of one-year-old children. J PLoS neglected tropical diseases 2015;9(3):e0003463.

10. Nampijja M, Apule B, Lule S, et al.; Effects of maternal worm infections and anthelminthic treatment during pregnancy on infant motor and neurocognitive functioning. 2012;18(6):1019-1030.

11. Allam AF, Farag HF, Lotfy W, et al.; Comparison among FLOTAC, Kato-Katz and formalin ether concentration techniques for diagnosis of intestinal parasitic infections in school children in an Egyptian rural setting. J Parasitology 2021;148(3):289-294. 
12. Addo HO, Addo KK, Bimi L; Water handling and hygiene practices on the transmission of diarrhoeal diseases and soil transmitted helminthic infections in communities in rural Ghana. J Civil Environmental Research 2014;6(1):68-79.

13. Ofosu HA, Ako-Nnubeng IT; The Impact of the School Based Deworming Program on Education in the Kwahu West Municipality of Ghana. Journal of Environment Earth Science 2014;4(3).

14. Abera A, Nibret E; Prevalence of gastrointestinal helminthic infections and associated risk factors among schoolchildren in Tilili town, northwest Ethiopia. Asian Pacific journal of tropical medicine 2014;7(7):525-530.

15. Davis SM, Worrell CM, Wiegand RE, et al.; Soil-transmitted helminths in pre-school-aged and schoolaged children in an urban slum: a cross-sectional study of prevalence, distribution, and associated exposures. The American journal of tropical medicine and hygiene 2014;91(5):1002.

16. Hotez PJ, Bundy DA, Beegle K, et al. Helminth infections: soil-transmitted helminth infections and schistosomiasis, 2006.

17. Humphries D, Mosites E, Otchere J, et al.; Epidemiology of hookworm infection in Kintampo North Municipality, Ghana: patterns of malaria coinfection, anemia, and albendazole treatment failure. The American journal of tropical medicine hygiene 2011;84(5):792.

18. Tay SCK, Gbedema SY, Gyampomah TK; Accuracy of diagnosis of intestinal helminth parasites in a reference diagnostic laboratory in the Ashanti Region of Ghana. International Journal of Parasitology Research 2011;3(1):12-16.

19. Mirisho R, Neizer ML, Sarfo B; Prevalence of intestinal helminths infestation in children attending Princess Marie Louise Children's Hospital in Accra, Ghana. Journal of parasitology research 2017;2017.

20. Kirwan P, Asaolu S, Abiona T, et al.; Soil-transmitted helminth infections in Nigerian children aged 025 months. Journal of Helminthology 2009;83(3):261-266.

21. Yap P, Du Z-W, Wu F-W, et al.; Rapid re-infection with soil-transmitted helminths after triple-dose albendazole treatment of school-aged children in Yunnan, People's Republic of China. The American journal of tropical medicine and hygiene 2013;89(1):23.

22. Jia T-W, Melville S, Utzinger J, et al.; Soil-transmitted helminth reinfection after drug treatment: a systematic review and meta-analysis. PLoS neglected tropical diseases 2012;6(5):e1621.

23. Benjamin-Chung J, Nazneen A, Halder AK, et al.; The interaction of deworming, improved sanitation, and household flooring with soil-transmitted helminth infection in rural Bangladesh. PLoS neglected tropical diseases 2015;9(12):e0004256.

24. Worrell CM, Wiegand RE, Davis SM, et al.; A cross-sectional study of water, sanitation, and hygienerelated risk factors for soil-transmitted helminth infection in urban school-and preschool-aged children in Kibera, Nairobi. PIOS One 2016;11(3):e0150744.

25. Freeman M, Chard A, Nikolay B, et al.; Associations between school-and household-level water, sanitation and hygiene conditions and soil-transmitted helminth infection among Kenyan school children. Parasites and vectors 2015;8(1):1-13. 
26. Gyasi SF, Boateng AA, Awuah E, et al.; Ellucidating the incidence and the prevalence of Schistosomiasis spp infection in riparian communities of the Bui dam. $J$ Journal of Parasitic Diseases 2019;43(2):276-288.

27. Haile D, Nigatu D, Gashaw K, et al.; Height for age z score and cognitive function are associated with Academic performance among school children aged 8-11 years old. Archives of Public Health 2016;74(1):1-7.

28. Ezeamama AE, Bustinduy AL, Nkwata AK, et al.; Cognitive deficits and educational loss in children with schistosome infection-a systematic review and meta-analysis. PLoS neglected tropical diseases 2018;12(1):e0005524.

29. Tandoh MA, Mills-Robertson FC, Wilson MD, et al.; Nutritional and cognitive deficits of school-age children: a study in helminth-endemic fishing and farming communities in Ghana. Nutrition Food Science 2019.

30. Stevens GA, Finucane MM, De-Regil LM, et al.; Global, regional, and national trends in haemoglobin concentration and prevalence of total and severe anaemia in children and pregnant and nonpregnant women for 1995-2011: a systematic analysis of population-representative data. The Lancet Global Health 2013;1(1):e16-e25.

\section{Figures}




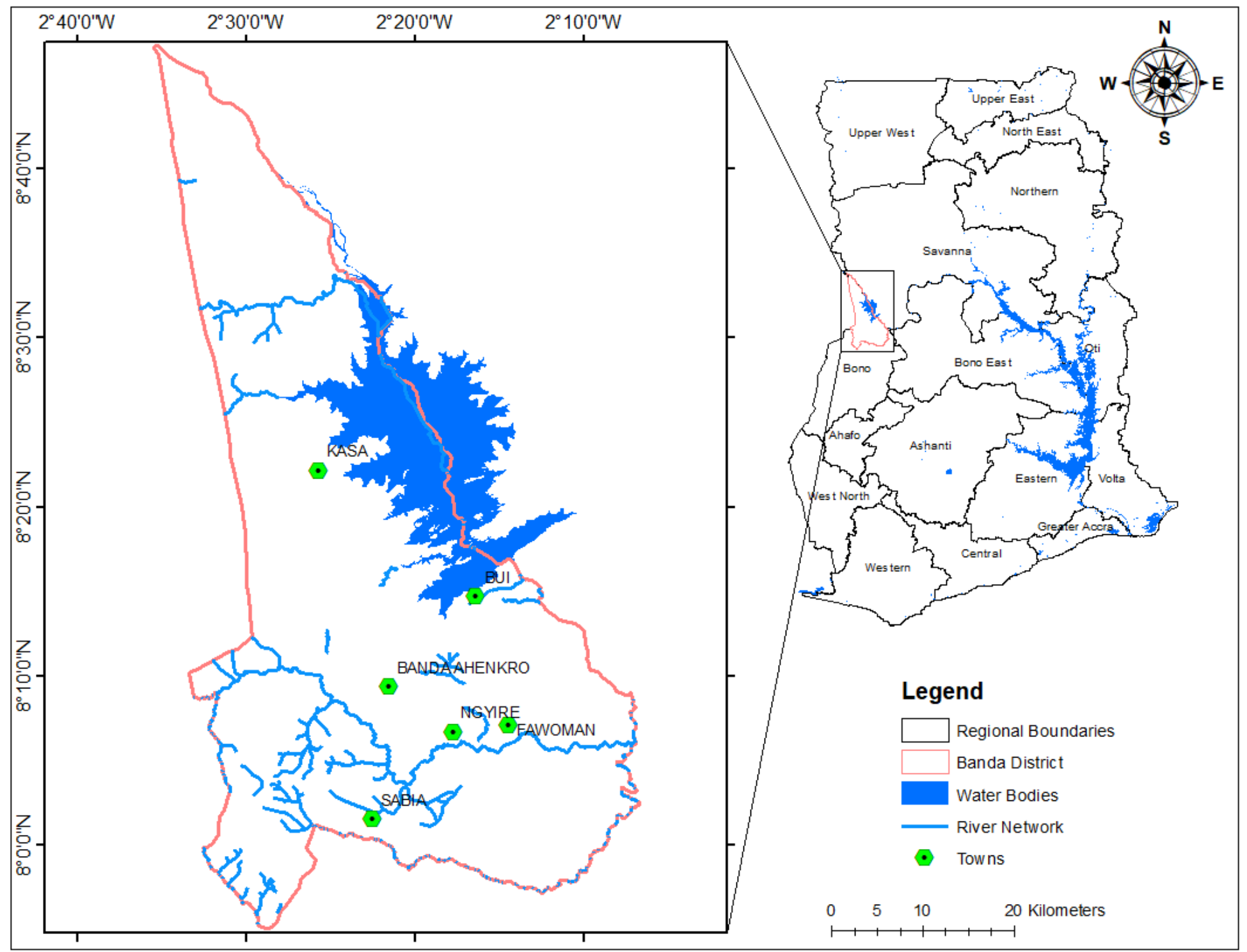

Figure 1

Map of Ghana showing study area. Credit EORIC, UENR 


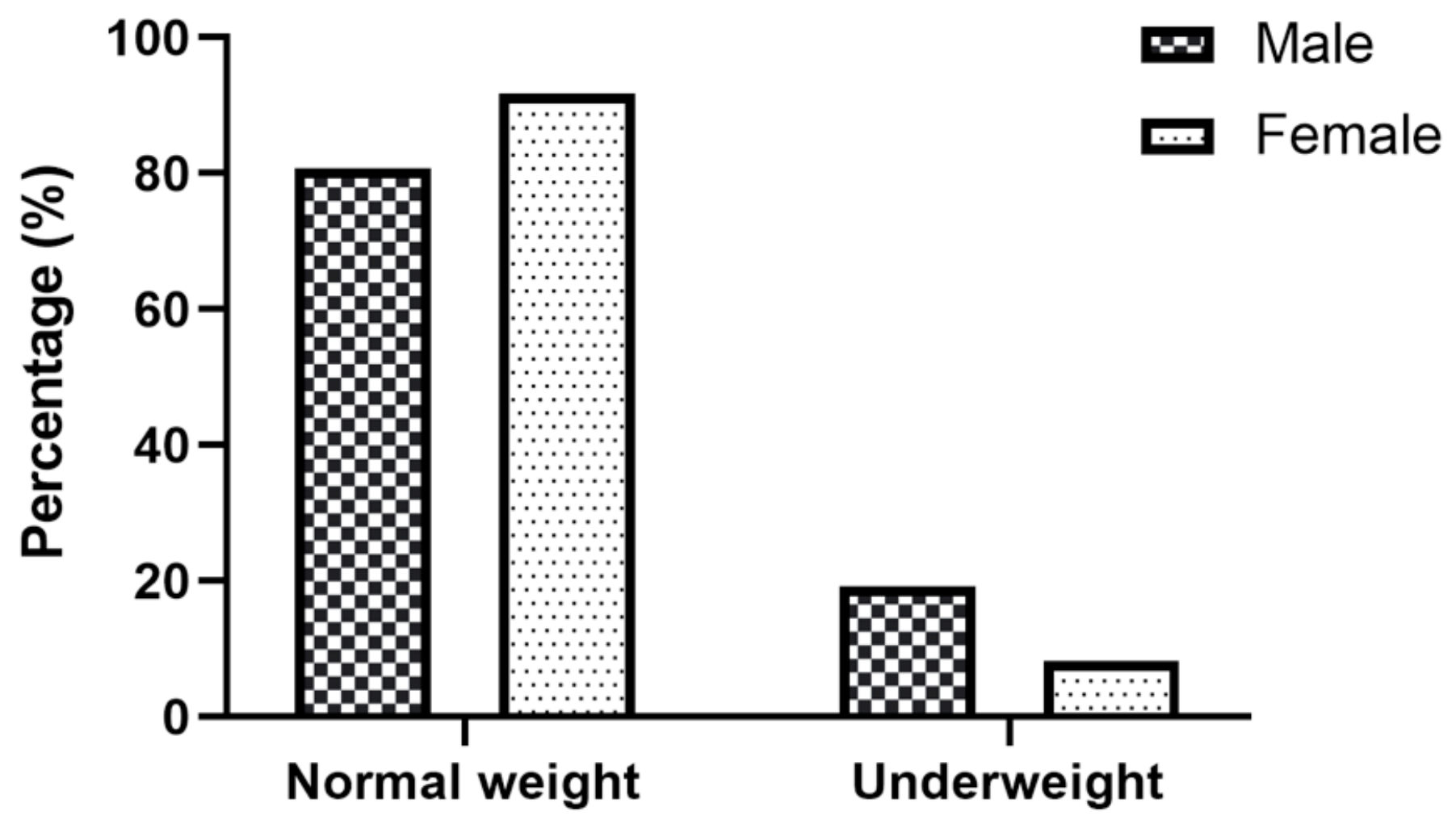

Figure 2

Nutritional status of school children.

\section{Supplementary Files}

This is a list of supplementary files associated with this preprint. Click to download.

- Additionalfile1bandaselectedschools.pdf

- Additionalfile2.docx 